\title{
A clustering approach to integrate traffic safety in road maintenance prioritization
}

\author{
Janstrup, Kira Hyldekær; Møller, Mette; Pilegaard, Ninette
}

Published in:

Traffic Injury Prevention

Link to article, DOI:

$10.1080 / 15389588.2019 .1580700$

Publication date:

2019

Document Version

Peer reviewed version

Link back to DTU Orbit

Citation (APA):

Janstrup, K. H., Møller, M., \& Pilegaard, N. (2019). A clustering approach to integrate traffic safety in road maintenance prioritization. Traffic Injury Prevention, 20(4), 442-448.

https://doi.org/10.1080/15389588.2019.1580700

\section{General rights}

Copyright and moral rights for the publications made accessible in the public portal are retained by the authors and/or other copyright owners and it is a condition of accessing publications that users recognise and abide by the legal requirements associated with these rights.

- Users may download and print one copy of any publication from the public portal for the purpose of private study or research.

- You may not further distribute the material or use it for any profit-making activity or commercial gain

- You may freely distribute the URL identifying the publication in the public portal

If you believe that this document breaches copyright please contact us providing details, and we will remove access to the work immediately and investigate your claim. 


\section{A clustering approach to integrate traffic safety in road maintenance prioritization}

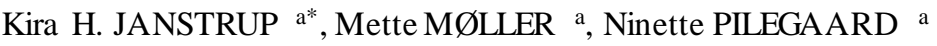

a Department of Management Engineering, Technical University of Denmark, Bygningstorvet 116B, 2800 Kgs. Lyngby, Denmark

E-mail: \{kija,mette,nipi\}@dtu.dk

* Corresponding author

Department of Management Engineering, Technical University of Denmark, Bygningstorvet 116B, 2800 Kgs. Lyngby, Denmark

Telephone: +45.45256526, E-mail: kija@dtu.dk 


\section{ABSTRACT}

Objectives: We combine data on roads and crash characteristics to identify patterns in road traffic crashes with regard to road characteristics. We illustrate how combined analysis of data regarding road maintenance, maintenance costs, road characteristics, crash characteristics, and its geographical location can enrich road maintenance prioritization with a traffic safety perspective.

Methods: The study is based on traffic crash data merged with road maintenance data and annual average daily traffic (AADT) collected in Denmark. We analyzed 3,964 crashes that occurred from 2010-2015. A Latent Class Clustering (LCC) technique was used to identify crash clusters with different road and crash characteristics. The distribution of crash severity and estimated road maintenance costs for each cluster was found and cluster differences were compared using the chi-square test. Finally, a map-matching procedure was used to identify the geographical distribution of the crashes in each cluster.

Results: Results showed that based on road maintenance levels there was no difference in the distribution of crash severity. The LCC technique revealed 11 crash clusters. Five clusters were characterized by crashes on roads with a poor maintenance level (levels 4 and 3). Only few of these crashes included a vulnerable road user (VRU) but many occurred on roads without barriers. Four clusters included a large share of crashes on acceptably maintained roads (level 2). For these clusters only small variations in road characteristics was found whereas the differences in crash characteristics were more dominant. The last two clusters included crashes which mainly occurred on new roads with no need for maintenance (level 1). Injury severity, estimated maintenance costs, and geographical location were found to be differently distributed for most of the clusters.

Conclusions: We find that focusing solely on road maintenance and crash severity does not give a clear guidance of how to prioritize between road maintenance efforts from a traffic safety perspective. However, when combined with geographical location and crash characteristics, a more nuanced picture appears which allows consideration of different target groups and perspectives.

Keywords: Traffic crash; road maintenance; prioritization; traffic safety; latent class clustering. 


\section{INTRODUCTION}

Road safety has generally improved over the past years, although the most recent research now indicates a plateau (WHO 2015). Road safety levels can be ass essed in several ways, but as stated by Wegman (2017), the most commonly used indicators include the number of traffic crashes, the number of causalities, and related negative consequences.

When considering the effect of infrastructure on road safety it is relevant to distinguish between initiatives to improve and change existing road infrastructure (e.g. cycle lanes, roundabouts, curvature) and initiatives to maintain existing road infrastructure (e.g. resurfacing and treatment of unevenness). The importance of maintaining existing road infrastructure has long been recognized, but results regarding the influence of specific elements are contradictory (for a review see Elvik et al. 2009). With regard to the safety impact of road maintenance, existing knowledge is comparably sparse. This may reflect that road maintenance and road safety are often considered separate areas, and a tendency to focus on the influence of isolated elements of the road condition (Lee et al. 2015). Nevertheless, studies indicate the importance of road maintenance for road safety from several perspectives. Examples include the influence of surface conditions, highlighting aspects such as pavement roughness and texture in dry and wet conditions (e.g. Pulugurtha et al. 2013), skid resistance (e.g. Kogbara et al. 2016), rut depth (Christensen \& Ragnøy 2006), and winter road maintenance (e.g. Usman et al. 2010) on motor vehicle crashes or pedestrian safety (e.g. Corazza et al. 2016).

However, while road maintenance is important for safety it is also costly. In Denmark the estimated road maintenance costs for roads maintained by the Danish government was 1 billion DKK (around 0.13 billion euro) in 2016 (The Danish Road Association 2017). The Danish government maintains only about five percent of the Danish road network, hence the actual costs are much larger. The importance of joint consideration of road investment and safety impact has been highlighted by Albalate et al. (2013). Further, research shows that knowledge-based optimization of road maintenance plans can reduce maintenance costs (Yu et al. 2015) and that it is important to look at the geographical location to make the maintenance as cost efficient as possible (Donev and Hoffmann 2018). However, more knowledge is needed that can qualify and support prioritizing between road maintenance initiatives (e.g. Cottrell et al. 2009; Agarwal et al. 2013)

The objectives of the study is to identify and analyze patterns in road traffic crashes based on road and crash characteristics. We use a clustering approach to identify crash clusters and afterwards analyze cluster differences in terms of road maintenance levels to see if injury severity, estimated maintenance costs, and geographical locations of the crashes are differently distributed. With this we investigate whether the combined information can be used to support road maintenance prioritization taking a traffic safety perspective into account.

\section{METHOD}

Three types of data are included: 1) crash data registered by the Danish Police derived from the Danish National Road Traffic Crash database; 2) road maintenance data registered by Aarhus Municipality; and 3) annual average daily traffic (AADT) derived from the Danish National Transport Model (NTM) (http://www.landstrafikmodellen.dk/dokumentation). The road maintenance data and crash data are from Aarhus 
Municipality from 2010-2015. Aarhus Municipality is the second largest municipality in Denmark. It has a population of 335,685 (2017) and contains a 1,290 km road network.

4,793 crashes were registered by the police during the study period. For each crash information on crash characteristics (e.g., level of severity, time of day, road user type, drunk driving) and the road and its surroundings (e.g., speed limit, number of lanes) was available. The severity level was classified according to the most severe road user injury in the crash: $1.0 \%$ included fatalities, $11.6 \%$ included severe injuries, $6.2 \%$ included light injuries, and 81.2\% included property damage only (PDO).

The categorization of the road maintenance data are based on a visual inspection performed by trained and certified auditors following national guidelines (The Danish Road Directorate, 2015). As part of the visual inspection a damage point for each road section is calculated according to the guidelines (Appendix 7) prepared by the Danish Road Directorate. The damage point is divided into intervals in close cooperation between the municipalities and experts from the Danish Road Directorate. Distinctions are made among four levels: 1) no road damage or new road $(\mathrm{Dp}=0) ; 2)$ a few road damages $(\mathrm{Dp}=] 0,1]) ; 3)$ numerous road damages $(\mathrm{Dp}=] 1,4])$; and 4) extensive road damage ( $\mathrm{Dp}=] 4, \infty[)$. The municipality us es the levels as an indication of how urgently it must maintain a specific road section: level 1 = no need; level 2 = should be considered; level 3 = necessary; and level 4 = urgent. The road maintenance data contained 9,214 observations with information on 1,567 road sections.

For this study Aarhus Municipality assisted in identifying the five costs categories:1) 0-6.7 EUR/ $\mathrm{m}^{2}$; 2) 6.8-67.0 EUR/m²; 3) 67.1-107.0 EUR/m²; 4) above 107.0 EUR/m²; and 5) no estimate. The estimated maintenance costs take road characteristics into account (e.g. type of asphalt and adapted road safety treatments). Road sections with maintenance level 1 will always belong to the first cost category.

For some roads (22.2\%), an exact AADT value was not available and the AADT was listed as “unknown”. However in all cases these roads were primary roads with an AADT below 10,000. Crash and road maintenance data were merged for 3,964 crashes based on road ID number, crash location, crash date, and date of visual road inspection. Due to missing information on crash locations for less severe crashes the rate for successfulmerging differed according to crash severity: fatality (95\%); severe injury (90\%); light injury (90\%); and PDO (81\%). The crash maintenance data were linked to NTM with ArcGIS to find the AADT value for the location of each crash. Sample characteristics for the merged data are provided in Table 1. First, a chi-square test was used to test if there for maintenance level were any differences in the distribution of crash severity. A significance level of 0.05 was used.

Table 1 Sample characteristics of the crash maintenance data

\begin{tabular}{llrr|llrr}
\hline Variable & Category & Count & Pct. & Variable & Category & Count & Pct. \\
\hline Severity & Fatality & 44 & 1.1 & Speed limit & $10-60 \mathrm{~km} / \mathrm{h}$ & 3021 & 75.2 \\
& Severe injury & 499 & 12.6 & & $70-90 \mathrm{~km} / \mathrm{h}$ & 943 & 23.8 \\
\cline { 5 - 7 } & Light injury & 265 & 6.7 & Number of & One & 235 & 5.9 \\
& PDO & 3156 & 79.6 & lanes & Two & 2268 & 57.2 \\
\hline
\end{tabular}




\begin{tabular}{|c|c|c|c|c|c|c|c|}
\hline \multirow[t]{2}{*}{ Drunk driving } & Yes & 291 & 7.3 & & Three & 240 & 6.1 \\
\hline & No & 3673 & 92.7 & & Four or more & 851 & 21.5 \\
\hline \multirow[t]{2}{*}{ VRU involved } & Yes & 1621 & 40.9 & & Other* & 370 & 9.3 \\
\hline & No & 2343 & 59.1 & \multirow{2}{*}{ Median barriers } & Yes & 546 & 13.8 \\
\hline \multirow[t]{7}{*}{ Crash type } & Single vehicle & 486 & 12.3 & & No & 3418 & 86.2 \\
\hline & Same direction & 797 & 20.1 & \multirow[t]{6}{*}{ AADT } & $<5000$ & 287 & 7.2 \\
\hline & Opposite direction & 194 & 4.9 & & $5001-10.000$ & 514 & 13.0 \\
\hline & Intersection (turn) & 1440 & 36.3 & & $10.001-15.000$ & 323 & 8.1 \\
\hline & Intersection (straight) & 434 & 10.9 & & $15.001-20.000$ & 684 & 17.3 \\
\hline & Pedestrian crash & 305 & 7.7 & & $20.001-25.000$ & 415 & 10.5 \\
\hline & Parking and object & 308 & 7.8 & & $>25.000$ & 860 & 21.7 \\
\hline \multirow{3}{*}{$\begin{array}{l}\text { Light } \\
\text { condition }\end{array}$} & Daylight & 2713 & 68.4 & & Unknown & 881 & 22.2 \\
\hline & Illumination & 1044 & 26.4 & \multirow[t]{2}{*}{ Road design } & Intersection** & 2161 & 64.5 \\
\hline & Darkness & 207 & 5.2 & & Straight & 1345 & 33.9 \\
\hline \multirow{3}{*}{$\begin{array}{l}\text { Road } \\
\text { condition }\end{array}$} & Dry & 2683 & 67.7 & & Curve & 144 & 3.6 \\
\hline & Wet & 998 & 25.2 & & Other*** & 157 & 4.0 \\
\hline & Slippery & 283 & 7.1 & Environment & Business street & 222 & 5.6 \\
\hline \multirow[t]{4}{*}{ Season } & Winter & 949 & 24.0 & & Industrial district & 456 & 11.5 \\
\hline & Spring & 933 & 23.5 & & Dense residential & 2075 & 52.4 \\
\hline & Summer & 931 & 23.5 & & Sparse residential & 1211 & 30.5 \\
\hline & Autumn & 1151 & 29.0 & \multirow{3}{*}{$\begin{array}{l}\text { Maintenance } \\
\text { level }\end{array}$} & 1 & 1017 & 25.7 \\
\hline \multirow[t]{2}{*}{ Weekend } & Yes & 791 & 20.0 & & 2 & 1438 & 36.3 \\
\hline & No & 3173 & 80.0 & & 3 & 746 & 18.8 \\
\hline \multirow[t]{6}{*}{ Time of day } & 6:00-8:59 & 629 & 15.9 & & 4 & 763 & 19.2 \\
\hline & 9:00-14:59 & 1162 & 29.3 & \multirow{5}{*}{$\begin{array}{l}\text { Maintenance } \\
\text { cost }\left(E U R / m^{2}\right)\end{array}$} & $0-6.7$ & 1645 & 41.5 \\
\hline & $15: 00-17: 59$ & 998 & 25.2 & & $6.8-67.0$ & 1023 & 25.8 \\
\hline & 18:00-21:59 & 479 & 12.1 & & 67.1-107.0 & 616 & 15.5 \\
\hline & $22: 00-5: 59$ & 696 & 17.6 & & $>107.0$ & 583 & 14.7 \\
\hline & & & & & Not estimated & 97 & 2.4 \\
\hline
\end{tabular}

*: Parking, playground, and pedestrian area. **: Intersection and roundabout. ${ }^{* * *}$ : Train track, parking area, and drive in/out.

Second, the data were analyzed using a Latent Class Clustering (LCC) approach for pattern recognition of the merged crash maintenance data. The LCC was based on an underlying statistical model that allowed 
calculating cluster probabilities and allowed overlap across clusters. We used the SAS procedure developed by Lanza et al. (2007). The number of clusters were determined by the use of the entropy value and the Bayesian Information Criterion (BIC) due to its superiority in terms of consistency and accuracy (e.g. Nylund et al. 2007).

Third, the crash cluster distribution for the two dependent variables, crash severity and maintenance cost, were tested with a chi-square test against the distribution of the total sample and against the distribution of each cluster with the same maintenance level. Again a significance level of 0.05 was used.

Final, the geographical location of the crashes belonging to each cluster was inspected to see if the crashes occurred on the same roads and geographical locations or scattered widely around the road network.

\section{RESULTS}

Our first focus is on the safety effect of the general maintenance level. The chi-square test showed no differences in the distribution of crash severity between the four maintenance levels. Therefore, to qualify prioritization between different road maintenance efforts from a safety perspective, a broader perspective not only based on road maintenance level is needed. We therefore continue with a LCC.

\section{LCC Results}

The LCC was performed using categorical indicators corresponding to different road and crash characteristics. According to the BIC, the LCC yielded 11 crash clusters with an entropy criterion at 0.89, which indicates a high certainty in the cluster distribution of observations. Figure I presents the prevalent features for each crash cluster (C1-C11) and Table II describes the characteristics as percentages of the crash clusters.

Table II Latent class characteristics based on the LCC analysis (percentage of crash cluster observation)

\begin{tabular}{|c|c|c|c|c|c|c|c|c|c|c|c|c|}
\hline \multirow{2}{*}{ Variable } & \multirow{2}{*}{ Category } & $\mathrm{C} 1$ & C2 & C3 & $\mathrm{C} 4$ & C5 & C6 & C7 & C8 & C9 & C10 & C11 \\
\hline & & 8.5 & 4.6 & 8.3 & 19.5 & 12.4 & 7.1 & 6.6 & 10.5 & 6.7 & 7.4 & 8.6 \\
\hline \multirow{4}{*}{$\begin{array}{l}\text { Maintenance } \\
\text { level }\end{array}$} & 1 & 14.0 & 22.3 & 35.2 & 21.5 & 19.6 & 43.6 & 57.7 & 20.8 & 27.1 & 20.3 & 17.8 \\
\hline & 2 & 29.9 & 24.7 & 25.6 & 43.1 & 47.7 & 25.3 & 19.9 & 42.7 & 28.3 & 44.6 & 40.0 \\
\hline & 3 & 54.1 & 16.7 & 7.1 & 19.3 & 15.9 & 12.4 & 2.9 & 20.0 & 18.1 & 19.9 & 15.3 \\
\hline & 4 & 2.0 & 36.3 & 32.1 & 16.1 & 16.7 & 18.7 & 19.5 & 16.5 & 26.5 & 15.1 & 26.9 \\
\hline \multirow[t]{2}{*}{ Speed limit } & $10-60 \mathrm{~km} / \mathrm{t}$ & 98.8 & 18.4 & 34.4 & 98.7 & 100. & 62.9 & 22.2 & 95.1 & 16.1 & 97.1 & 98.5 \\
\hline & $70-90 \mathrm{~km} / \mathrm{t}$ & 1.2 & 81.6 & 65.6 & 1.3 & 0.0 & 37.1 & 77.8 & 4.9 & 83.9 & 2.9 & 1.5 \\
\hline \multirow{5}{*}{$\begin{array}{l}\text { Number of } \\
\text { lanes }\end{array}$} & One & 0.7 & 6.1 & 0.3 & 8.4 & 9.7 & 0.0 & 0.0 & 8.0 & 8.7 & 8.3 & 8.2 \\
\hline & Two & 15.7 & 63.0 & 47.0 & 70.1 & 72.5 & 25.3 & 18.8 & 67.3 & 69.0 & 71.6 & 75.5 \\
\hline & Three & 9.7 & 11.3 & 9.7 & 5.1 & 1.3 & 7.9 & 6.1 & 3.0 & 18.0 & 3.2 & 0.6 \\
\hline & Four or more & 62.0 & 16.0 & 37.0 & 8.9 & 2.6 & 60.0 & 67.6 & 12.5 & 3.3 & 1.7 & 0.0 \\
\hline & Other* & 11.8 & 3.5 & 6.0 & 7.6 & 13.9 & 6.9 & 7.4 & 9.2 & 1.0 & 15.1 & 15.8 \\
\hline \multirow{2}{*}{$\begin{array}{l}\text { Median } \\
\text { barriers }\end{array}$} & Yes & 89.7 & 0.0 & 4.3 & 5.6 & 6.6 & 22.7 & 0.0 & 14.6 & 0.1 & 4.3 & 5.6 \\
\hline & No & 10.3 & 100. & 95.7 & 94.4 & 93.4 & 77.3 & 100. & 85.4 & 99.9 & 95.7 & 94.4 \\
\hline AADT & $<5000$ & 1.4 & 24.4 & 4.3 & 10.0 & 6.0 & 5.6 & 0.0 & 5.1 & 17.7 & 5.5 & 4.9 \\
\hline
\end{tabular}




\begin{tabular}{|c|c|c|c|c|c|c|c|c|c|c|c|c|}
\hline & $5001-10.000$ & 3.8 & 36.0 & 10.7 & 12.5 & 11.7 & 8.9 & 2.5 & 18.0 & 21.4 & 15.9 & 10.8 \\
\hline & $10.001-15.000$ & 5.1 & 16.6 & 11.5 & 9.0 & 7.4 & 5.5 & 3.7 & 8.6 & 12.4 & 7.9 & 4.6 \\
\hline & $15.001-20.000$ & 37.7 & 0.1 & 19.3 & 12.3 & 16.9 & 19.4 & 25.0 & 14.9 & 6.5 & 17.8 & 19.2 \\
\hline & $20.001-25.000$ & 4.2 & 0.0 & 16.7 & 11.8 & 9.9 & 14.6 & 17.5 & 12.6 & 5.4 & 8.6 & 8.2 \\
\hline & $>25.000$ & 46.3 & 1.8 & 36.9 & 13.1 & 15.7 & 42.8 & 51.4 & 15.2 & 6.0 & 9.2 & 12.2 \\
\hline & Unknown & 1.5 & 21.0 & 0.6 & 31.2 & 32.4 & 3.2 & 0.0 & 25.7 & 30.6 & 35.1 & 40.2 \\
\hline \multirow[t]{4}{*}{ Environment } & Business street & 3.3 & 0.0 & 0.1 & 6.3 & 11.5 & 0.5 & 0.0 & 7.7 & 0.0 & 15.0 & 8.3 \\
\hline & Industrial district & 9.0 & 9.3 & 19.4 & 12.6 & 12.4 & 12.4 & 25.0 & 7.0 & 2.0 & 5.8 & 10.4 \\
\hline & Dense residential & 74.8 & 6.3 & 20.8 & 69.6 & 63.6 & 48.5 & 16.9 & 72.9 & 2.4 & 61.3 & 66.5 \\
\hline & Sparse residential & 12.9 & 84.4 & 59.7 & 11.4 & 12.5 & 38.6 & 58.1 & 12.4 & 95.6 & 17.9 & 14.8 \\
\hline \multirow[t]{4}{*}{ Road design } & Intersection** & 80.8 & 94.4 & 29.2 & 87.1 & 14.6 & 81.3 & 93.0 & 70.4 & 3.6 & 22.9 & 11.4 \\
\hline & Curve & 0.4 & 0.0 & 0.8 & 0.0 & 7.3 & 0.5 & 0.0 & 0.2 & 24.0 & 1.6 & 10.0 \\
\hline & Straight & 13.8 & 2.4 & 69.2 & 3.2 & 62.7 & 18.2 & 2.7 & 22.1 & 70.6 & 59.1 & 66.1 \\
\hline & Other*** & 5.0 & 3.2 & 1.0 & 9.7 & 15.4 & 0.0 & 4.3 & 7.3 & 1.8 & 16.4 & 12.5 \\
\hline \multirow[t]{2}{*}{ Drunk driving } & Yes & 1.8 & 1.5 & 0.2 & 1.3 & 8.6 & 20.8 & 1.2 & 4.5 & 17.4 & 1.1 & 29.6 \\
\hline & No & 98.2 & 98.5 & 99.8 & 98.7 & 91.4 & 79.2 & 98.8 & 95.5 & 82.6 & 98.9 & 70.4 \\
\hline \multirow[t]{2}{*}{ VRU involved } & Yes & 45.7 & 16.6 & 4.6 & 72.3 & 11.2 & 6.4 & 61.5 & 67.3 & 6.0 & 100. & 12.9 \\
\hline & No & 54.3 & 83.4 & 95.4 & 27.7 & 88.8 & 93.6 & 38.5 & 32.7 & 94.0 & 0.0 & 87.1 \\
\hline \multirow[t]{7}{*}{ Crash type } & Single vehicle & 2.8 & 3.3 & 3.0 & 0.3 & 22.0 & 19.8 & 1.7 & 0.0 & 61.3 & 0.0 & 37.9 \\
\hline & Same direction & 21.2 & 0.0 & 90.6 & 1.8 & 33.9 & 31.3 & 0.1 & 4.0 & 10.0 & 21.8 & 15.3 \\
\hline & Opposite direction & 1.1 & 0.0 & 3.1 & 0.3 & 12.4 & 1.5 & 0.0 & 0.2 & 23.3 & 7.1 & 8.6 \\
\hline & Intersection (turn) & 60.0 & 63.1 & 1.9 & 74.8 & 2.9 & 31.9 & 70.9 & 49.4 & 0.0 & 15.9 & 0.1 \\
\hline & $\begin{array}{l}\text { Intersection } \\
\text { (straight) }\end{array}$ & 10.1 & 33.6 & 0.6 & 22.6 & 1.1 & 13.3 & 14.9 & 19.3 & 0.0 & 0.0 & 0.0 \\
\hline & Pedestrian crash & 4.2 & 0.0 & 0.0 & 0.0 & 0.0 & 0.2 & 11.2 & 27.1 & 0.0 & 50.7 & 0.0 \\
\hline & Parking and object & 0.6 & 0.0 & 0.8 & 0.2 & 27.8 & 2.0 & 1.2 & 0.0 & 5.4 & 4.5 & 38.1 \\
\hline \multirow{3}{*}{$\begin{array}{l}\text { Light } \\
\text { conditions }\end{array}$} & Daylight & 90.1 & 87.7 & 94.1 & 100. & 100. & 3.4 & 92.0 & 0.0 & 51.6 & 99.6 & 0.2 \\
\hline & Illumination & 9.9 & 0.0 & 3.0 & 0.0 & 0.0 & 96.6 & 8.0 & 92.7 & 8.7 & 0.1 & 88.4 \\
\hline & Darkness & 0.0 & 12.2 & 2.9 & 0.0 & 0.0 & 0.0 & 0.0 & 7.3 & 39.7 & 0.4 & 11.4 \\
\hline \multirow{3}{*}{$\begin{array}{l}\text { Road } \\
\text { condition }\end{array}$} & Dry & 75.3 & 64.4 & 65.0 & 77.1 & 78.6 & 52.0 & 77.4 & 43.7 & 48.0 & 83.9 & 63.7 \\
\hline & Wet & 21.7 & 29.2 & 30.5 & 21.5 & 15.0 & 37.5 & 17.5 & 47.5 & 23.1 & 11.7 & 26.0 \\
\hline & Slippery & 3.0 & 6.4 & 4.6 & 1.4 & 6.4 & 10.4 & 5.2 & 8.8 & 28.9 & 4.5 & 10.4 \\
\hline \multirow[t]{2}{*}{ Season } & Winter & 19.9 & 20.0 & 23.1 & 11.9 & 17.7 & 40.5 & 15.8 & 46.1 & 37.0 & 16.8 & 28.6 \\
\hline & Spring & 26.4 & 28.2 & 22.2 & 22.7 & 30.2 & 12.6 & 33.3 & 15.4 & 20.0 & 28.7 & 21.7 \\
\hline
\end{tabular}




\begin{tabular}{llrrrrrrrrrrr} 
& Summer & 25.9 & 21.9 & 20.6 & 32.9 & 31.2 & 13.4 & 27.6 & 5.0 & 22.3 & 30.5 & 14.8 \\
& Autumn & 27.8 & 29.9 & 34.1 & 32.6 & 20.9 & 33.5 & 23.4 & 33.5 & 20.7 & 23.9 & 34.9 \\
\hline \multirow{2}{*}{ Weekend } & Yes & 14.8 & 19.2 & 11.2 & 12.8 & 23.1 & 39.0 & 10.2 & 24.6 & 25.6 & 14.1 & 32.4 \\
& No & 85.2 & 80.8 & 88.8 & 87.2 & 76.9 & 61.0 & 89.8 & 75.4 & 74.4 & 85.9 & 67.6 \\
\hline \multirow{2}{*}{ Time of day } & 6:00-8:59 & 16.4 & 15.8 & 20.4 & 22.0 & 12.8 & 4.8 & 18.0 & 20.8 & 17.3 & 13.2 & 4.1 \\
& 9:00-14:59 & 40.9 & 33.8 & 44.5 & 42.0 & 41.4 & 0.0 & 38.0 & 0.0 & 20.4 & 46.3 & 0.0 \\
& 15:00-17:59 & 31.7 & 37.2 & 32.5 & 27.7 & 29.8 & 13.1 & 32.8 & 19.9 & 16.7 & 29.5 & 6.2 \\
& 18:00-21:59 & 7.3 & 9.9 & 2.6 & 7.1 & 13.4 & 23.7 & 8.5 & 25.0 & 14.0 & 10.1 & 14.1 \\
& $22: 00-5: 59$ & 3.7 & 3.2 & 0.0 & 1.3 & 2.5 & 58.4 & 2.7 & 34.3 & 31.5 & 0.9 & 75.5 \\
\hline
\end{tabular}

*: Parking, playground, and pedestrian area. **: Inters ection and roundabout. ${ }^{* *}$ : Train track, parking area, and drive in/out.

In the following the LCC results are presented starting with the crashes occurring on roads with an urgent need for maintenance.

\section{Crashes on roads with a necessary or urgent need for maintenance (level 3 and 4)}

With regard to crashes that occurred on maintenance level 4 roads, the clusters C2, C3, C9, and C11 include a high number ( $>25 \%)$. Differences in road and crash characteristics exist, however, some common features are also found. All four clusters include crashes that occurred on roads with no barriers and only a small number involve VRU's.

Road characteristics for these clusters differ mostly according to speed limit and AADT. The speed limit for C11 is $10-60 \mathrm{~km} / \mathrm{h}$. The remaining three clusters include crashes on 70-90 km/h roads. The AADT varies between the clusters: In C11 the AADT is unknown for many roads; in C3 the AADT is high $(>25,000)$; and C2 and C9 include roads with a low AADT $(<10,000)$. Regarding the crash characteristics, C2 mostly includes intersection crashes (with and without turn) occurring in daylight, and on a dry surface between 9 am and 6 pm. Cluster C3 has similar crash characteristics to C2, except for the crash type. A large share of the crashes involve two parties driving in the same direction on the same road. The remaining two clusters, C9 and C11, both consist of many drunk driving crashes (17.4\% and $29.6 \%$, respectively). The main differences between the clusters regard light and surface conditions. Many C9 crashes occurred on dark roads with a slippery or wet surface, whereas C11 crashes mainly occurred on illuminated roads and on a dry surface.

For crashes occurring on maintenance level 3 roads, only C1, includes a high percentage (54.1\%). The crashes mainly occurred on 10-60 km/h roads, roads with four or more lanes, with median barriers (89.7\%), a very high AADT (>25,000), in a dense residential area, in an intersection with one party turning $(60.0 \%)$, in daylight, and on a dry road between 6am and 6pm.

\section{Crashes on roads with an acceptable need for maintenance (level 2)}

With regard to crashes on maintenance level 2 roads, five clusters (C4, C5, C8, C10, and C11) include a high percentage $(\geq 40 \%)$. The road characteristics are similar but the crash characteristics differ widely. The road characteristics include a speed limit of 10-60 km/h; two lanes; no median barrier; dense residential environment; 
Figure I Features and percentages of the most prevalent characteristics of each crash cluster (C1-C11*) divided according to maintenance level.

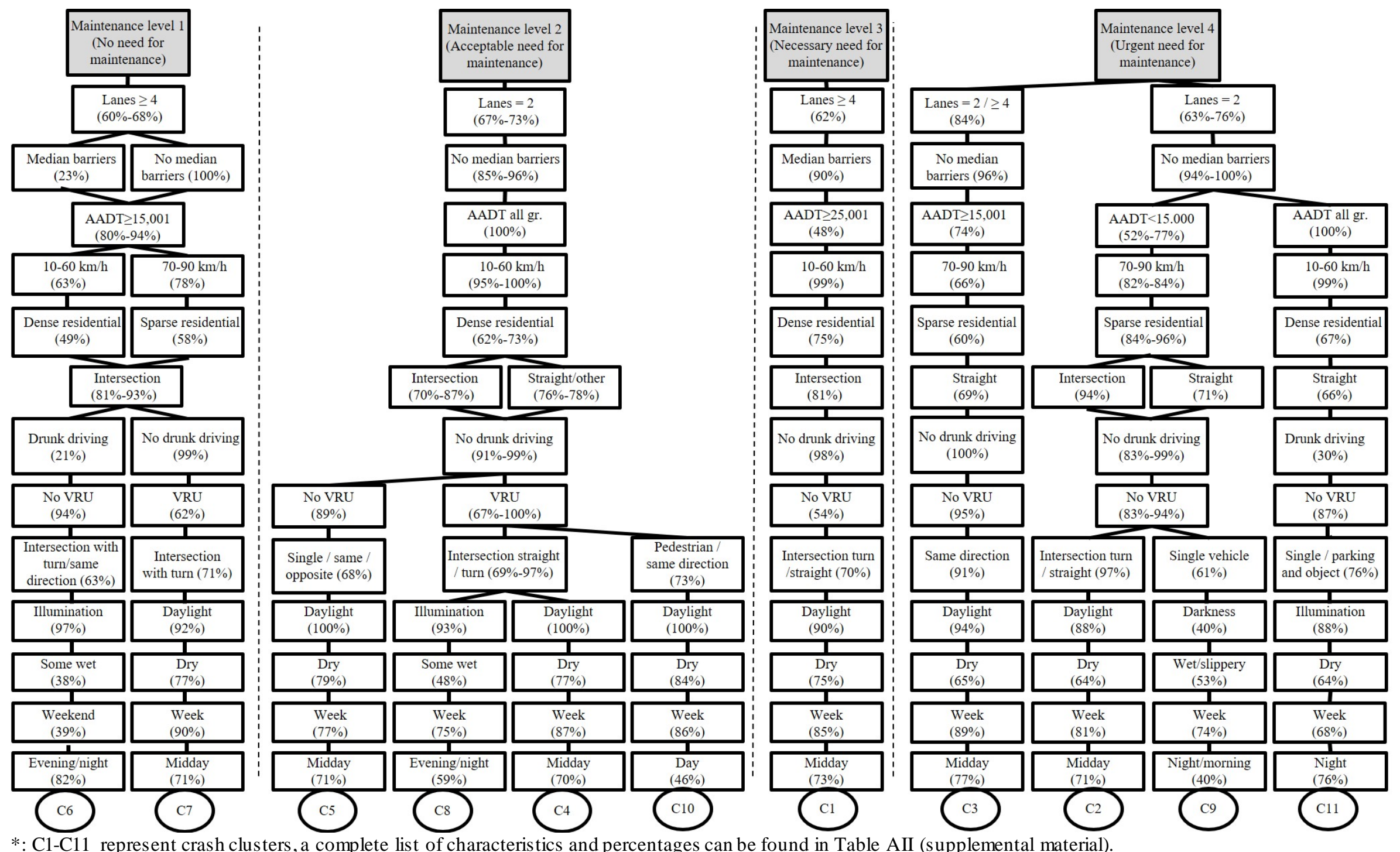

*: C1-C11 represent crash clusters, a complete list of characteristics and percentages can be found in Table AII (supplemental material). 
and AADT values in all categories including "unknown”. With regard to crash characteristics, all clusters included a low percentage of drunk driving crashes. Except C5 the clusters all include a large share (>67.3\%) of VRU crashes. The crashes in three clusters (C4, C5, and C10) mostly occurred in daylight on a dry surface, whereas many C8 crashes occurred on a wet surface (47.5\%). With regard to crash type the clusters differ greatly. C4 includes intersection crashes with one party turning; C5 includes many single-vehicle crashes, collisions with a parked car or an object, and crashes with two vehicles driving on the same road in same direction. C8 is characterized by inters ection and pedestrian crashes. The highest percentage of pedestrian crashes is found in C10 (50.7\%).

\section{Crashes on roads with no need for maintenance}

C6 and C7 crashes relatively often happen on maintenance level 1 roads. The crashes often happen on larger roads (four lanes or more, AADT>15,000), but differ widely according to road and crash characteristics.

\section{Maintenance Cost, Injury Severity and Geographical Location}

Crash severity and maintenance cost were not included in the LCC since the categorical indicators were assumed to be endogenous, hence no covariates are employed to predict cluster membership. The characteristics for injury severity and maintenance cost are presented in Table III for each cluster.

For maintenance level 4 clusters, the distribution of the crash severity in C2 is not significantly different from the total sample. C3 and C11 include more PDO crashes compared with C9, which includes more crashes with fatalities. Regarding road maintenance costs, a significant difference was found for C3 and C11 compared with the total sample, and between C2 and C3, C3 and C9, and C3 and C11. C3 includes a lower share of high maintenance costs roads ( $>107.0 \mathrm{EUR} / \mathrm{m}^{2}$ ) compared with all other maintenance level 4 clusters. The estimated road maintenance costs are higher for C11 compared with the total sample, but there is no significant difference between C11 and C2, and C11 and C9.

Table III Severity characteristics and maintenance costs of the crash clusters (percentage of cluster observations)

\begin{tabular}{llrrrrrrrrrrr}
\hline \multirow{2}{*}{ Variable } & Category & C1 & C2 & C3 & C4 & C5 & C6 & C7 & C8 & C9 & C10 & C11 \\
\cline { 3 - 9 } & & 8.5 & 4.6 & 8.3 & 19.5 & 12.4 & 7.1 & 6.6 & 10.5 & 6.7 & 7.4 & 8.6 \\
\hline Severity & Fatality & 0.6 & 2.3 & 0.0 & 0.5 & 0.6 & 0.4 & 2.0 & 1.0 & 5.4 & 1.6 & 0.6 \\
& Severe injury & 11.7 & 16.5 & 4.3 & 14.7 & 4.6 & 5.4 & 17.3 & 19.6 & 13.0 & 27.7 & 5.2 \\
& Light injury & 8.4 & 7.4 & 4.3 & 9.1 & 3.8 & 2.9 & 9.8 & 8.4 & 4.6 & 8.7 & 3.8 \\
& PDO & 79.2 & 73.9 & 91.3 & 75.6 & 91.0 & 91.3 & 71.0 & 71.1 & 77.0 & 61.9 & 90.5 \\
\hline $\begin{array}{l}\text { Maintenance } \\
\text { cost }\end{array}$ & 0-6.7 & 59.3 & 30.7 & 43.5 & 36.5 & 35.6 & 54.7 & 62.4 & 37.1 & 40.6 & 34.2 & 34.1 \\
& 6.8-67.0 & 25.3 & 31.3 & 33.2 & 26.5 & 23.1 & 19.9 & 18.8 & 27.3 & 26.8 & 26.1 & 25.7 \\
& 67.1-107.0 & 1.5 & 15.9 & 18.9 & 17.0 & 17.3 & 15.6 & 16.1 & 16.7 & 17.2 & 16.8 & 15.6 \\
& $>107.0$ & 10.5 & 18.8 & 3.1 & 17.4 & 21.7 & 7.6 & 0.8 & 15.8 & 15.3 & 18.7 & 22.3 \\
& No estimate & 3.3 & 3.4 & 1.2 & 2.5 & 2.3 & 2.2 & 2.0 & 3.1 & 0.0 & 4.2 & 2.3 \\
\hline
\end{tabular}


The distribution of the injury severity of the crashes in C1 (maintenance level 3) is not significantly different compared with the total sample. However, the maintenance costs are significantly lower (0-6.7 $\left.\mathrm{EUR} / \mathrm{m}^{2}\right)$.

Figure II Map-matching of crash clusters with crashes that occurred on roads with a necessary or urgent need for maintenance (C1, C2, C3, C9, and C11).

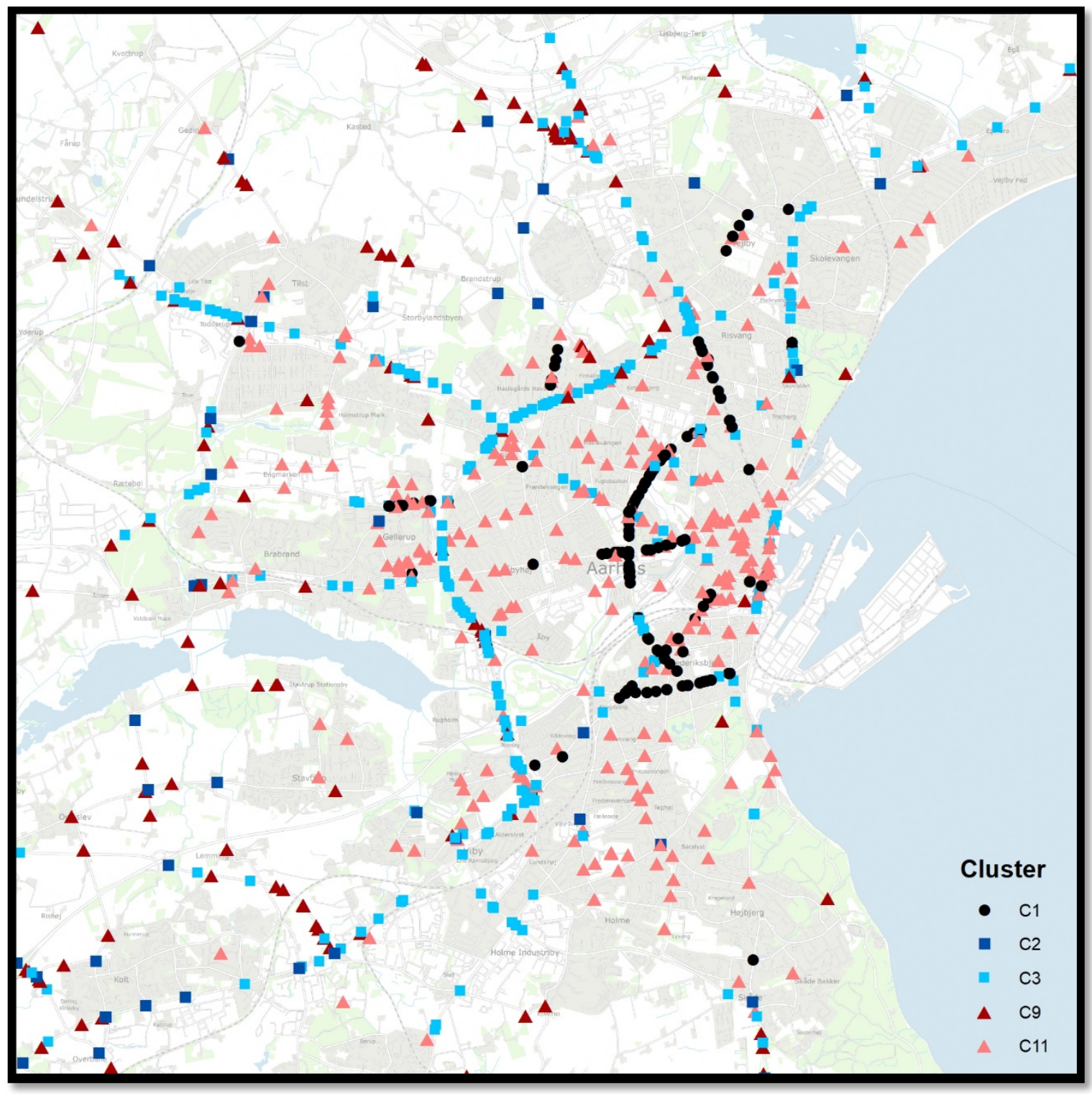

For the clusters characterized by maintenance level 2 (C4, C5, C8, and C10), the distribution of the severity degree is significantly different from the total sample. C5 mainly consists of PDO crashes, whereas C4, C8, and C10 include a significantly higher share of severe and light-injury crashes. The maintenance costs for C4 and C8 are not significantly different, while the maintenance costs for C5 and C10 are different compared with the total sample. C5 and C10 both include a higher share of roads with high maintenance costs (>107.0 $\left.\mathrm{EUR} / \mathrm{m}^{2}\right)$ and a lower share of roads with low maintenance costs $\left(0-6.7 \mathrm{EUR} / \mathrm{m}^{2}\right)$.

There is no significant difference regarding estimated maintenance costs between the two maintenance level 1 clusters (C6 and C7). Both clusters include fewer roads with very high maintenance costs (>107.0 EUR/m²) and 
more roads with low maintenance costs $\left(0-6.7 \mathrm{EUR} / \mathrm{m}^{2}\right)$. However, both clusters have a significantly different severity distribution compared with the total sample, and compared with the distribution between the two clusters. C6 includes many PDO crashes and fewer severe and light-injury crashes compared with C7.

When adding the geographical location of the crashes to the maintenance level 3 and 4 clusters (C1, C2, C3, C9 and C11) it becomes clear that some clusters include several crashes that occurred on the same road section (see Figure II). C1 mainly includes crashes close to the city centre and C3 crashes occurred in a line around the inner city. C9 crashes (including the highest share of severe injury crashes and fatalities), occurred on roads outside the city centre mainly on rural roads. C11 also includes many rural road crashes, but the roads are different from C9. C2 crashes are located in different geographical areas and is thus the only cluster with no clear geographical pattern.

\section{DISCUSSION}

The purpose was first to identify patterns in road traffic crashes with regard to different road and crash characteristics. Second, to analyze cluster differences regarding road maintenance levels, to see if injury severity, estimated maintenance costs, and the geographical locations of the crashes was differently distributed, and if the combined information could support road maintenance prioritization from a traffic safety perspective.

As no significant difference in crash severity distribution according to maintenance level was found, the results show that to include road safety in a nuanced manner in road maintenance prioritization, e.g. focusing on specific target groups, prioritization based solely on maintenance level is not sufficient. Rather, a more multifaceted approach which allows additional road and crash characteristics to be considered is relevant.

The LCC revealed 11 crash clusters, five of which included a high percentage of crashes occurring on roads with an urgent need for maintenance. Significant differences regarding the distribution of crash severity and maintenance costs were found for the majority of clusters compared with the total sample of crashes. Mapmatching identified road sections with a high concentration of crash occurrence.

With regard to the clusters with a large share of crashes on roads with an urgent need for maintenance (levels 3 or 4) the map-matching proved to be relevant for road maintenance prioritization. With the exception of $\mathrm{C} 2$, the majority of the crashes within each cluster occurred in a specific geographical area. Therefore the costtreatment of maintaining C2 road sections could be higher than for the road sections in the other clusters due to a scattered geographical distribution (Donev and Hoffmann 2018).

Speed has a high effect on crash severity (OECD/ITF 2018) and the road safety effect of road maintenance on high-speed (70-90 km/h) and low-speed (10-60 km/h) roads should be considered separately. C3 and C9 included a high share of 70-90 km/h speed limit crashes. However, in C9 crashes many other risk factors such as drunk driving (e.g. Ogden and Moskowitz 2004) or wet and slippery surfaces (e.g. Pulugurtha 2013) existed; thus, the influence of maintenance level is less clear. Crashes often result from an unfortunate interplay between the road, the road user, and the vehicle (e.g. Møller and Haustein 2016; Shinar 2017), and a poorlymaintained road may increase the risk of a drunk driver losing control of the vehicle. C9 crashes are more severe with a higher percentage of fatalities and a lower AADT compared with C3. However, based on the cluster characteristics results indicate that in order to prevent these crashes a combined preventive effort including road maintenance and efforts to reduce risk-taking behavior such as drunk driving is needed. 
The two crash clusters (C1 and C11) with crashes occurring on low speed limit roads (10-60 km/h) differ according to road and crash characteristics. Regarding road characteristics, C1 crashes mainly occurred on roads with median barriers which could have an effect on crash frequency and severity (Elvik 1995; Tarko et al. 2008). However, as the effect of median barriers depends on the type e.g., concrete, steel, cable (Zou et al., 2016) and our data did not include this information, the impact of the barriers is not possible to asses. Although the detailed information on the specific damages on the road sections was not available, the cluster characteristics of $\mathrm{C} 1$ indicate that well maintained roads in residential areas are of key importance for the safety of VRU also for intersection accidents. Further detailed studies are needed to verify this.

The results show that if preventing fatal accidents is a priority, maintaining C9 road sections should be prioritized. The highest number of fatalities was included in this cluster, and a high number of these crashes occurred on roads with an urgent need for maintenance (level 4), the findings confirm that poor road conditions and the number of fatality crashes are related (Chan et al. 2010; Dozza and Werneke 2014; Lee et al. 2015).

Maintenance of less-damaged roads may well be cost-efficient, as additional maintenance costs later can be avoided (Burningham and Stankevich 2005). Further, in line with previous results (see Janstrup et al., 2018) the high share of VRU crashes on roads with an acceptable need for maintenance (level 2) indicates that even minor road damages may be critical for VRU and therefore relevant to maintain. The results show that maintenance prioritization between maintenance level 2 clusters should be based on crash characteristics since cluster differences regarding road characteristics are limited. With regard to the crash characteristics, C5 differs from the other three clusters, as the involvement of VRU is comparably low. Poor maintenance level increases the crash risk for a cyclist tenfold (Dozza and Werneke 2014), and focus on road environment and maintenance is recommended in order to lower the injury degree for pedestrians (Corazza et al. 2016). Due to a large share of VRU maintenance of C4, C8, and C10 roads should therefore be prioritized. However, C4 and C8 also included a high share of intersection crashes; and although this crash situation is frequent among VRU (e.g. Zegeer \& Bushell 2012; Møller and Haustein 2016), the impact of road maintenance may be smaller, as road user factors such as looked-but-failed-to-see (e.g. Herslund and Jørgensen 2003) and impairment or risk-taking behavior (e.g. Aust et al. 2012) are also of key importance. Therefore, maintenance of C10 road sections may have the highest road safety impact. This is supported by the fact that all C10 crashes involved a VRU, 50\% were pedestrians, and the number of severe injury crashes was much higher compared with all other clusters.

The two clusters on roads with no need for maintenance differ widely according to road and crash characteristics, this indicates that crashes on well-maintained roads are perhaps more influenced by the behavior of the road user.

In this study, the effect of road maintenance on crash risk has not been our focus. The aim has been to provide support for road maintenance prioritization from a safety perspective, considering crash severity and frequency, road characteristics, and AADT. The results show that even though road characteristics of roads needing maintenance are similar, the crash characteristics are often different. This highlights the importance of taking crash characteristics into account in road maintenance prioritization. The methodology and results are easily transferable to other municipalities or on a national level, as long as the data collection is similar.

Geographical information was included, but a similar analysis covering other areas can be done, as long as important, country-specific variables are included. The multifaceted understanding provided by the analysis 
allows stakeholders to make informed decisions regarding road maintenance prioritization, taking specific road safety aspects into account, such as crash type (e.g., single vehicle crashes, intersection crashes), road usertype (e.g., bicyclist, pedestrian, motorists), and crash severity.

Three limitations are worth mentioning. First, the geographical area included was limited and additional studies on larger geographical areas are relevant. However, due to high quality data, the results are expected to be robust. Second, high levels of underreporting, particularly regarding less severe crashes (Janstrup et al. 2016) may influence the results. Successful data-merging was lowest for less severe crashes, and the effect of road maintenance level on the PDO crashes may be higher. To test this, a larger sample with additional municipalities is needed. Alternatively, crash data from insurance companies, which are expected to include many more PDO crashes, could be included. However, such data are currently not available. Lastly, as detailed information on the circumstances related to each crash was not available, the specific impact of the road condition could not be assessed.

\section{ACKNOWLEDGEMENTS}

Financial support from the Danish Asphalt Association and the Safer Roads Association in Denmark is gratefully acknowledged.

\section{REFERENCES}

Agarwal PK, Jain V, Bhawsar U. Development of a hierarchical structure to identify critical maintenance components affecting road safety.Procedia Soc Behav Sci. 2013;104:292-301.

Albalate D, Fernández L, Yarygina A. The road against fatalities: Infrastructure spending vs. regulation?? Accid Anal Prev. 2013;59:227-239.

Appendix 7, Beregning af skadespoint, Available at: https://www.fmk.dk/fileadmin/user_upload/By_Land_og_Kultur/Natur_og_Landskab/Vej_og_Trafik/U dbud_2/Bilag_7_Beregning_af_skadespoint.pdf.pdf

Aust ML, Fagerlind H, Sagberg F. Fatal intersection crashes in Norway: Patterns in contributing factors and data collection challenges. Accid Anal Prev. 2012;46:782-791.

Burningham S, Stankevich N. Why road maintenance is important and how to get it done. Transport Notes, NO TRN-4, 2005. Available at: https://siteresources.worldbank.org/INTTRANSPORT/Resources/3362911227561426235/5611053-1231943010251/TRN4_Road_Maintenance.pdf

Chan CY, Huang B, Yan X, Richards S. Investigating effects of asphalt pavement conditions on traffic accidents in Tennessee based on the pavement management system(PMS). J Adv Transp. 2010;44:150-161.

Christensen P, Ragnøy R. Vegdekkets tilstand og trafiksikkerhet (the condition of the road surface and safety). TØI Report 840/2006. Oslo Transportøkonomisk Institutt, 2006.

Corazza MV, Mascio PD, Moretti L. Managing sidewalk pavement maintenance: A case study to increase pedestrian safety. Journal of Traffic and Transportation Engineering. 2016;3(3):203-214.

Cottrell WD, Bryan S, Chilukuri BR, Kalyani V, Stevanovic A, Wu J. Transportation infrastructure maintenance management: Case study of a small urban city. Journal of Infrastructure Systems. 2009;120-132.

Donev V, Hoffmann M. From cause-specific treatment selection on single road sections to 
work-zone optimization with user and external costs. Proceedings of 7th Transport Research Arena TRA. 2018. Available on https://zenodo.org

Dozza M, Werneke J. Introducing naturalistic cycling data: What factors influence bicyclists' safety in the real world? Transportation Research Part F. 2014;24:83-91.

Elvik R. The safety value of guardrails and crash cushions: A meta-analysis of evidence from evaluation studies. Accid Anal Prev. 1995;27(4):523-549.

Elvik R, Høye A, Vaa T, Sørensen M. Road Design and Road Equipment. In: Elvik R, Høye A, Vaa T, Sørensen M. The handbook ofroad safety measures. $2^{\text {nd }}$ ed. United Kingdom; Emerald Group Publishing Limited; 2009: 145-334.

Herslund M, Jørgensen NO. Looked-but-failed-to-see-errors in traffic. Accid Anal Prev. 2003;35:885-891.

Janstrup KH, Kaplan S, Hels T, Lauritsen J, Prato CG. Understanding traffic crash under-reporting: Linking police and medical records to individual and crash characteristics. Traffic Injury Prevention. 2016;17(6):580-584.

Janstrup KH, Møller M, Pilegaard N. The road and its influence on bicycle accidents in Denmark. Proceedings of 7th Transport Research Arena TRA. 2018. Available on https://zenodo.org/record/1456589

Kaplan S, Prato CG. Cyclist-motorist crash patterns in Denmark: A latent class clustering approach. Traffic Injury Prevention. 2013:14;725-733.

Kogbara RB, Masad EA, Kassem E, Scarpas AT, Anupam K. A state-of-the-art review of parameters influencing measurement and modeling of skid resistance of asphalt pavements. Construction and Building Materials. 2016;114(1):602-617.

Lanza ST, Collins LM, Lemmon DR, Schafer JL. PROC LCA: A SAS procedure for latent class analysis. Structural Equation Modeling. 2007;14:671-694.

Lee J, Nam B, Abdel-Aty M. Effects of pavement surface conditions on traffic crash severity. J. Transp. Eng. 2015;141(10):1-11.

Møller, M, Haustein, S. Factors contributing to young moped rider accidents in Denmark. Accid Anal Prev. 2016;87:1-7.

Nylund KL, Asparouhov T, Muthén BO. Deciding on the number of classes in latent class analysis and growth mixture modeling: a Monte Carlo simulation study. Struct Equation Modeling. 2007;14:535-569.

OECD/ITF. Speed and Crash Risk. IRTAD Research Report. 2018. Available at: https://www.itf-oecd.org/speedcrash-risk

Ogden, EJ, Moskowitz. Effects of alcohol and otherdrugs on driver performance. Traffic Injury Prevention. 2004;5:185-198.

Prato CG, Gitelmn V, Bekhor S. Mapping patterns of pedestrian fatal accidents in Israel. Accid Anal Prev. 2012;44:56-62.

Pulugurtha SS, Ogunro V, Pando MA, Patel KJ, Bonsu A. Preliminary results towards developing thresholds for pavement condition maintenance: Safety Perspective. Procedia Soc Behav Sci. 2013;104:302-311.

Shinar D. Accident /crash causation and analysis. In: Shinar D. Traffic Safety and Human Behavior $2^{\text {nd }}$ ed. United Kingdom: Emerald publishing limited 2017: 18:1039-1084. 
Tarko AP, Villwock NM, Blond N. Effect of median design on rural freeway safety: flush medians with concrete barriers and depressed medians. Transportation Research Record. 2008;2060:29-37.

The Danish Road Association. Asfaltudgifterne i 2017. Available at:

http://www.dv.dk/ files/Dokumenter/internerapporter/asfaltudsigterneiforslagtilfinanslov2017.pdf. 2017.

The Danish Road Directorate. Målevejledning af drift- og vejvedligeholdelse. Vejteknisk Institut. 2015;1-35.

Usman T, Fu L, Miranda-Moreno LF. Quantifying safety benefit of winter road maintenance: Accident frequency modelling. Accid Anal Prev. 2010;42:1878-1887.

Wegman F. The future of road safety: A worlwide perspective. IATTS Research. 2017;40:66-71.

WHO. Global Status Report on Road Safety. 2015. Available at: http://www.who.int/violence_injury_prevention/road_safety_status/2015/en/

Yu B, Gu X, Ni F, Guo R. Multi-objective optimisation for asphalt pavement maintenance plans at project level: Integrating performance, cost and environment. Transportation Research Part D. 2015;41:64-74.

Zegeer CV, Bushell M. Pedestrian crash trends and potential countermeasures from around the world. Accid Anal Prev. 2012;44:3-11.

Zou Y, Tarko AP. An insight into the performance of road barriers - redistribution of barrier-relevant crashes. Accid Anal Prev. 2016;96:152-161. 